\title{
Making a contemporary contribution using old data: reflections on delayed doctorates
}

\begin{abstract}
It is not unusual for doctoral research to take a long time to complete - not only because of the work involved but also because of delays caused by other factors. This can apply to any research, but it is something that can particularly afflict a doctorate. Noting how an intended empirically-based contribution to knowledge sits between a changing world and changing literature, this reflective piece identifies and explores the issues involved when the age of the data collected might cast doubt on the ability of the research to make a contemporary contribution to knowledge. The article concludes with advice for supervisors and their research students.
\end{abstract}

Brian May completed most of his $\mathrm{PhD}$ in Astrophysics in Jim Ring's group at Imperial College in 1970-4. Previously he had completed his degree in Physics at Imperial. As far back as 1968 he had formed a band called 'Smile' with Tim Staffell and Roger Taylor, which after the departure of Tim Stafell and with the addition of Freddie Mercury and John Deacon, became 'Queen'. With the launch of the 'Queen II' album in 1974, Queen started to have an international success, and Brian abandoned his PhD.

Despite the demands of Queen, Brian retained his love of astronomy, and appeared regularly on Patrick Moore's TV programme 'Sky at Night'.

Following published interviews in 2006 in which he talked about wanting to complete his PhD, the Head of Astrophysics at Imperial at the time, Michael Rowan-Robinson, contacted Brian to suggest he might like to come and talk about this. Brian responded enthusiastically and he was re-registered for his $\mathrm{PhD}$, under Michael's supervision, from October 1st 2006. At the time Brian estimated it would take him two years to complete, but he in fact submitted his revised $\mathrm{PhD}$ on August 2nd 2007. As well as writing up the work he had done in 1970-4, observations of the kinematics of the zodiacal dust cloud made from the island of Tenerife, Brian also had to review the work on zodiacal dust during the intervening 33 years, which included the discovery of the zodiacal dust bands by the IRAS infrared astronomical satellite. After a viva ${ }^{1}$ on Aug $23 \mathrm{rd}$, the revised thesis ${ }^{2}$ was approved on Sept 24th 2007, almost exactly 37 years after it had been commenced. (http://astro.ic.ac.uk/bmay/home, accessed $7^{\text {th }}$ June 2017)

\footnotetext{
${ }^{1}$ A viva voce, or oral, examination, sometimes called a thesis defence.

${ }^{2}$ This is the standard UK term for what in some other countries is referred to as a 'dissertation'.
} 


\section{Introduction}

Although it is a particularly striking example, both for the length of the delay (more than 30 years) and the reason for it (a career as lead guitarist with a legendary rock band), Brian May's is not the only example of a $\mathrm{PhD}$ that has used empirical data considerably later than originally planned. Many factors can delay a doctorate: progress on the research is just slower than anticipated (Finn, 2005); the doctoral experience itself is found to be challenging (Jones, 2013); the supervisory relationship works badly; illness strikes or mental health issues arise (Levecque et al., 2017); a new job is taken before 'writing up' is complete (Phillips \& Pugh, 2015); or external factors, such as job-related responsibilities (Petre \& Rugg, 2010) or family issues, interfere. Part-time students, who are more common in business and management studies than in many other fields, face particular challenges (Gardner \& Gopaul, 2012) - in addition to the lengthier period they are expected to take, which is apt to render the data older by the time submission occurs anyway. Van de Schoot et al. (2013) identify three categories of reasons for variation in $\mathrm{PhD}$ completion or time-to-degree: institutional or environmental factors, including field of study and departmental climate; characteristics of the $\mathrm{PhD}$ candidate, including gender and some of the issues identified above; and the nature and quality of supervision, which is one of the most important influences - for good or ill - on research student outcomes (Baptista et al., 2015).

Delay can lead to non-completion or attrition (van de Schoot et al., 2013), which has been increasingly recognised as a problem in recent years (Golde, 2000; Lahenius, 2012). Whatever the particular reasons for delay, there are probably many doctorates - and potential journal articles for that matter - that have been abandoned in the belief that the data are no longer capable of providing the basis for a contribution to knowledge. In addition to worrying about how the field of study itself has developed, researchers in business and management studies often have a particular concern that natural scientists (such as Brian May) tend not to 
have, namely that the world to which the data relate has also moved on to such an extent that the scope for making a significant contribution might have been fatally undermined. The doctorate might not just be delayed, but defunct.

With old data, the worry might be clear; but whether and how to pursue the doctorate to submission might not be. Recognising that supervisors - or 'advisers', as they are known in some countries (Halse \& Malfroy, 2010) - can have an important impact on completion and time-to-degree (Baptista et al., 2015; Halse \& Malfroy, 2010; van de Schoot et al., 2013), the aim of this paper is to identify the key issues in determining whether a contemporary contribution might be possible using old data and to provide guidance for those who confront such a situation. The issues will be framed in the context of a $\mathrm{PhD}$, but much of the discussion is also relevant to other doctorates, such as DBAs (Farrell et al., 2018) - and, indeed, to journal publications proceeding from doctoral research or other substantial projects. In pursuing this aim, I reflect on some of my own experience as a doctoral supervisor dealing with research students and their delayed projects. Reflection on their experience by supervisors is not unusual in the literature on doctoral research (e.g., ParkerJenkins, 2018).

The remainder of the paper is organised as follows. In the next section three 'vignettes' drawn from my own supervisory experience in a business school are presented. The following two sections then identify and frame the key issues to be addressed in determining whether and how it might be possible to secure a sufficient contribution to knowledge using old data, in relation to the literature and the world to which the data relate, respectively. Given that it is not just a supervisor and their research student who might be concerned about the age of the data, but also examiners, who have the final word, a further section then focuses on the examination stage. Thus the paper views doctoral students and their supervisors as facing challenges on three fronts as they seek a viable way forward: the 
academic literature; the empirical world; and the eventual examiners. Finally, the Conclusion summarises the key points and proffers some advice.

\section{Three vignettes}

In this section, three anonymised vignettes based on my supervision experience within a UK business school are presented. The vignettes are not claimed to represent the full range of possible problems and solutions, but they do help to prompt thinking and illustrate the points subsequently made. In each case, although I was the main supervisor when submission took

place, I had not been involved with the initiation of the research. Indeed, in two of the cases I began supervising only after the data had been collected and substantial analysis had been conducted. Although there was a sense on the candidates' part that things could have been done differently, there is no intention in this piece to level any criticism at them or previous supervisors; these were not 'rescue supervisions' in the sense used by Biggs (2005). Instead, the purpose is to learn from the successful experience of using very old empirical data to obtain a $\mathrm{PhD}$. The vignettes have been constructed from my recollections rather than from notes made at the time, but each person has approved the vignette that describes their experience. Some details have been reduced in specificity to preserve anonymity, but other than the change of names, no material has been fictionalised. Each person also had sight of a completed version of the paper prior to submission. This process was approved by the Business School's Research Ethics Panel.

\section{$\underline{2.1 \text { Juno }}$}

The data were about 20 years old by the time the $\mathrm{PhD}$ thesis was submitted. Both the original supervisors had left the university: one had retired and subsequently died; the other had 
returned to her commercial career, from which the industry links that provided the sites for fieldwork had been obtained. The delay in the PhD had occurred for a number of reasons. Juno had been appointed to a full-time lectureship while still a PhD student; she had been given, and indeed embraced, a heavy teaching load and other responsibilities; she gave birth to two children and moved on to a fractional contract for a time; and she also suffered a period of serious ill-health. None of the reasons was decisive in isolation. Indeed, the candidate herself would admit that things could have been other than they were. However, that was the situation she found herself in: with very old data and the desire, if not a burning one, to complete a PhD and move on with her career, including the opening up of new research vistas better suited to her current teaching portfolio and academic interests.

I became involved with the project long after the data had been collected. The candidate had done a considerable amount of work, but the analysis was rather applied in nature and, moreover, related to a commercial situation that no longer existed: she had been examining supply chain-related issues, but technological change had completely changed both the operations and structure of the industry. However, it seemed to me that the data were good. The question was: were they good for a PhD? The research had involved modelling network relationships across supply-related organisations in order to implement ideas associated with business network reengineering (BNR), which itself was a development of business process reengineering (BPR). While radical change in the industry meant that the outputs of the analysis were no longer of any direct relevance, an updated literature review demonstrated that the critique of different network modelling tools was still of value, as was the approach used to capture processes and network relationships.

Although Juno had previously written a considerable amount of material, much of it had to be jettisoned or radically re-written to ensure that the contents of the thesis were thoroughly consistent with new aims and objectives. The examiners were subsequently satisfied that 
Juno's thesis demonstrated a sufficient contribution to the contemporary body of knowledge in the area.

\section{$\underline{2.2 \text { Julius }}$}

Julius embarked on $\mathrm{PhD}$ research into the impact of the 'fundholding' initiative on general medical practitioners (GPs) in the UK's National Health Service (NHS) (Coulter, 1995; Ennew et al., 1998). I became the supervisor in the early stages of the project on joining the Business School as Professor of Accounting. A series of interviews conducted by Julius with both GPs and support staff such as practice managers led to a set of case studies, with the fruits of the analysis being published in refereed academic journals. However, other commitments at the university, including promotion to a campus-wide leadership role in response to a government initiative, led to the research being put to one side, although Julius continued to write and publish a little on other topics.

It was many years later that he returned to the research with a view to completing his $\mathrm{PhD}$. Not surprisingly, we had concerns about the age of the data. The earlier publications could demonstrate that an academic contribution, but one not yet recognised by the award of a research degree, had been made, but we decided to add a longitudinal element to the research by returning to the GPs, where possible, to have them reflect in interviews on their experience of fundholding and their careers since that date. The interviews in due course led

to a further refereed journal article, but more importantly they gave a contemporary aspect to the thesis, the overall argument of which provided a full role for the earlier empirical data which by this point were about 15 years old. 


\section{$\underline{2.3 \text { Augustus }}$}

While working at a university in another part of the UK, Augustus had collected the data for an economic input-output analysis of the local economy. After that, he became an employee of, and re-registered at, my own university. Several years later he submitted his $\mathrm{PhD}$ thesis, but by Augustus' own admission, it was rather rushed to meet the submission deadline, in spite of the amount of time that had passed, and insufficiently clear about the intended contribution. The examiners were accordingly rather severe with it, at which point I became involved. Following constructive conversations with Augustus, I became the main supervisor.

We both realised that the thesis needed significantly reworking and, in particular, had to be clear about, and make, a worthwhile contribution to knowledge. The problem was that the content of the input-output analysis, even if it might once have provided the basis for a successful $\mathrm{PhD}$ submission, was no longer of any real interest, since the local economy that he had modelled had changed significantly in the meantime. The collection of new data would have been difficult, if not impossible, not least because Augustus had only twelve months in which to revise and resubmit his thesis - and there was much work to be done, even without collecting further data. Nevertheless, the modelling that he had done was interesting, in that it employed a way of doing input-output analysis that had been set aside by researchers many years before. Using the rather dated analysis of the local economy, Augustus was able to argue that scholars had jettisoned the approach needlessly and showed how it might be taken forward for future studies. The contribution thus became about how to do input-output analysis, with the local economy of many years ago simply a worked example. Following a viva examination in which he cogently argued his case, Augustus was awarded his $\mathrm{PhD}$. 


\subsection{Conclusion}

As current members of academic staff, Juno, Julius and Augustus were part-time doctoral students, and the vignettes reflect many of the familiar issues that can delay completion of a doctorate, including ill health, family responsibilities and job changes. Their projects sought to make an empirical contribution to knowledge by offering sufficient novel insight into the world that was not yet reflected in the academic literature. Yet their data were, in research terms, very old, having typically been collected $15-20$ years earlier.

Julius' was perhaps the easiest to deal with. First, he had already secured a contribution to the literature, and examiners tend to associate $\mathrm{PhD}$ originality with 'publishability' (Clarke \& Lunt, 2015). Second, he was able to acquire more recent data, though this entailed not only an update of his previous literature review but also a review of a new stream of literature that was opened up by the new data.

In the cases of Juno and Augustus, though, it was impractical, if not impossible, to update their data. However, they were able to use the old data to demonstrate the feasibility of novel approaches to their respective topics. Like Brian May, they had to ensure that they were fully apprised of the current state of the relevant literatures, both of which had been actively developing since their projects were first proposed and the data collected. As Wisker (2015) comments, the literature review is the place where doctoral authors engage with the theory and theoretical perspectives underlying their research, as a crucial step in establishing their own contribution to knowledge.

The three vignettes thus demonstrate that a $\mathrm{PhD}$ may be achieved with very old data, and they illustrate some of the ways in which that might be possible. Whatever the particular route to completion, analysis of ageing research data sits between the social world and the academic literature. The problem in such a situation is that either the world or the literature, or both, 
might have changed significantly since the data were collected. The next two sections address the challenge of securing a sufficiently significant contribution to knowledge in such circumstances, examining the issues relating to developments in literature and changes in the world, respectively.

\section{Facing the literature}

Literature coverage is an important element of doctoral assessment (Holbrook et al., 2015). As indicated in the comments on the three vignettes, a crucial task, if a contemporary contribution is to be made, is to check the current state of the literature. Similarly, Brian May had to review the research on zodiacal dust that had been published during the intervening three decades or so, the conclusion of which must have been that analysis of his existing data still had something to contribute.

If the literature is found to have dealt fully with the issue that the research was designed to tackle, there is a major problem, since an original contribution to knowledge (Clarke \& Lunt, 2014) cannot be claimed. Indeed, it is always a worry for a doctoral researcher that they will be 'pipped at the post' (Cryer, 2000, 218) or 'scooped' - a worry that increases the longer that submission is delayed. If the project is a non-empirical one, such as a mathematical proof, a development in the literature might prove fatal. However, where there is some uniqueness in the research data of an empirical project, there often remains the possibility of making a contribution, perhaps by modifying the research questions and the analysis. This might entail a recognition that the contribution will be less significant than originally planned - but hopefully it will still be sufficient. As Cantwell and Scevak (2004) note, it is widely recognised that a doctorate does not have to be 'ideal' but simply 'passable', a point 
emphasised by Mullins and Kiley (2002). Although examiners appreciate work of the highest standard, they are only seeking a threshold of competence (Golding, 2017).

If all the original research questions have, in effect, been answered since the data collection was undertaken, then the scope for proceeding with the doctorate will appear severely limited. Nevertheless, it is possible that different research questions - whether ones that could have arisen from the original literature review or ones that are prompted by more recent work - could be answered using the existing data (e.g. a study of relationships between variables that had not originally been envisaged). Moreover, if one or more of the original research questions remain valid, the chance of making a sufficient contribution to knowledge is increased. Most likely, some elements of the original proposal will still be feasible, even if they are not enough, on their own, for a 'passable' PhD.

The extent to which the current literature has closed off the agenda originally envisaged when the doctorate was planned will depend on several factors. One is the number of researchers working in the area. For example, medical science receives huge amounts of funding. Its many active researchers - a good proportion of whom are in dedicated research teams - tend to ensure that a research area moves forward relatively rapidly, thus increasing the probability that old data will not be able to form the basis for a contemporary contribution, at least in the form originally envisaged. However, business and management studies, as a research area, tends not have legions of post-doctoral researchers financed by external funding, and so it can take many years to work out a research seam. Even if some more recent work comes close to the candidate's research, it is likely that it is only broadly similar (Cryer, 2000). Another factor is fashion: a topic can go out of fashion, and the research community moves on before all the possible significant research questions are dealt with. If fashion is the issue, then publishing in the more prestigious journals might be a problem, because the perceived value of the contribution will be reduced. However, that should not affect whether the contribution 
is deemed sufficient for a doctorate. Sometimes an issue in a particular literature can be profitably returned to, even after other researchers have moved on having come to a particular consensus, as was the case with Augustus' PhD.

Finally, some topics are just difficult to research empirically. In such a situation, a research student who has been able to collect data is in a relatively strong position - and should be encouraged accordingly, since it is not always easy for an inexperienced researcher to recognise the value of their research data. As pointed out by a journal editor, an 'old' sample would be considered acceptable if the work is based on 'private/specific/original data that date from several years ago' but for which the phenomenon being studied is still of current interest (Stolowy, 2017, 415).

In addition to not recognising the value of their data, a research student can also feel awkward about addressing research questions that were not envisaged when the data were collected. New or modified research questions, with implications for the data analysis and discussion, mean that the thesis can feel contrived, perhaps even dishonest, since it does not accord with the way the research was planned. This is not unusual, though, because many projects depart significantly from what was originally planned; research seldom goes according to plan (Cryer, 2000) and 'messiness' is often experienced (Lambotte \& Meunier, 2013). The key is to remember that the thesis is a document of the present, aimed at a contemporary contribution. There can be an admission, perhaps in the introduction or in the research methods chapter, that the data were collected some time ago with a (slightly) different objective in mind, but the fundamental nature of a thesis is that it presents an argument or narrative arc that seeks to secure a contribution to the current body of literature, not that it is a chronological account of the research experience.

One way of thinking about pursuing new or significantly modified research questions is to view the existing data as being somewhat akin to secondary data. Typically, secondary 
analysis entails the analysis of data that others have collected, but Bryman and Bell (2015) comment that it can be difficult to know where the divide between primary and secondary analysis falls, if a researcher collects and analyses data and then some time later decides to rework the data. They argue that the later stage of activity may be viewed as secondary analysis; it is more a question of the data having been collected for some other purpose rather than by someone else. Although secondary analysis is often thought of in terms of quantitative data, it has increasingly been recognised as a possibility for qualitative data too (Heaton, 2008). A consideration of the issues that relate to secondary data analysis might be helpful when thinking about the modification or addition of research questions to be addressed through previously collected data. Such thinking can reduce the feeling of awkwardness or discomfort that might otherwise arise, and perhaps be debilitating, when analysing data for purposes and in ways that were not originally envisaged. It can help in a number of ways.

First, this perspective on old data can help legitimise use of the data in the mind of the student. Many 'normal' doctoral theses and published articles engage in secondary analysis of existing research data (Bryman \& Bell, 2015). Second, consideration of the old data as secondary data should help to clarify thinking about how it can be used and the limitations and challenges of doing so. This can all be part of the important process of re-orienting thinking about the doctoral thesis, helping to eradicate inappropriate 'legacy thinking' related to previous plans. ${ }^{3}$ One of the issues surrounding the re-analysis of data, though, is whether it is ethical to do so, The more the research questions are amended, the greater the chance that there could be a problem, depending on the details of the informed consent that had

\footnotetext{
${ }^{3}$ It might have helped that in two of the vignettes I was a new supervisor at a late stage of the project, bringing a fresh perspective. Juno, in particular, had to jettison a great deal of previous analysis as we endeavoured to keep the new aim of the thesis clearly in view.
} 
previously been obtained, if that is a factor. This will need to be considered, but at least the associated ethical issues tend to be reduced, or even sidestepped, when the data are being reanalysed by the person to whom it was provided. Depending on how the research was set up, perhaps the researcher should go back to the body that approved their research and, if appropriate, contact any parties that originally gave informed consent.

Finally, in addition to being up-to-date with the academic substance of the body of literature to which the thesis is intended to contribute, it is important to ensure that the analysis is up to current standards; analysis, whether quantitative or qualitative, can be seen to progress and develop over the years, as well as being subject to fashions. The degree of re-analysis required will affect the amount of time taken to submit and, hence, the further ageing of the data - but hopefully not too much. For example, if the data, either as collected or as subsequently processed, is in quantified form that can be analysed by means of a statistical package, the amount of time for the re-analysis might be quite limited, although the candidate might need some time to develop their methodological understanding. More demanding might be the re-analysis of qualitative data to reflect developments in relevant analytical methods. 


\section{Facing the world}

It is not only the literature that changes. A further concern might be that the world has moved on, leaving behind the context to which the empirical data related. This would not appear to be a problem in the natural sciences. The nature of the universe had presumably not changed in a significant way since Brian May made his observations more than 30 years earlier. Things can be more problematic in the social sciences though; and it might be a particular problem with the dynamic world to which business and management doctorates relate especially for a DBA, with its professional agenda.

One possible response is to update the data. If the data are readily available secondary data, such as official statistics, then that should not be too difficult. Indeed, the research might actually be strengthened by a longer time series. Moreover, not to include the more recent data might incur the disapprobation of the examiners. Stolowy (2017) notes that journal desk rejections tend to result when data have not been updated, even though publicly available; doctoral examiners might take a similarly dim view.

The greater problem relates to primary data. While the use of secondary data can involve cost (e.g. of acquisition) and effort (e.g. cleaning), it is recognised that the collection of primary data tends to be much more demanding (Cowton, 1998; Frankfort-Nachmias et al., 2015; Stewart \& Kamins, 1993). As noted earlier, the mere creation of a set of primary data can be a significant achievement in itself and might be looked on favourably by the examiners, as well as increasing the probability of still being able to make a contribution; and to do it again might be impractical. Indeed, in Augustus' case it really was not feasible in the time available for him to save his PhD. Even more extreme was Juno's case, where the organisations, and indeed the industry set-up, no longer existed. However, perhaps with some modification of, or addition to, the original research questions, the idea of a partial update might be possible as in Julius' case, whose more recent interviews not only 'refreshed' the data but also 
provided a welcome longitudinal aspect to the project, as well as opening up a new academic vista.

A further case that can be made for the acceptability of older data is that, in certain types of research, it is the relationships between variables that are of prime interest (Bryman \& Bell, 2015). While the descriptive statistics might be out of date, the relationships between them are likely to endure for longer, which might be of relevance to either theory testing or, especially, theory building, for in the latter case the size of the quantitative relationships might be of limited interest anyway. However, any such case should be argued on its merits rather than just assumed.

Perhaps methodological contribution is the final possibility. Such a contribution is ideally a supplementary offering, but when the data are getting old, it might need to play a greater role than would otherwise have been the case, and it will need to be argued for all the more convincingly. ${ }^{4}$ For reasons explained earlier, such a contribution had to loom particularly large in the case of Augustus' $\mathrm{PhD}$; fortunately, a good case was made for it. Juno's PhD thesis also offered valuable lessons about applied research methods suited to a particular set of managerial ideas.

\section{Facing the examiners}

The crucial thing about a doctoral thesis is not just that it should demonstrate the research competence of the candidate but that it should make a sufficient contribution to knowledge at the time of submission. The balance between these two elements tends to vary between countries, but the provision of an original contribution to knowledge is generally important

\footnotetext{
${ }^{4}$ I confess that, based on previous $\mathrm{PhD}$ examining experience, I tend to be rather sceptical when a candidate claims an additional, methodological contribution, so I recognise the challenge of using this tactic.
} 
(Baptista et al., 2015). The previous sections sought to identify and explore the issues that are likely to arise when the empirical data analysed in a thesis are significantly older than would ideally by the case. In this section, it will be assumed that the supervisor ${ }^{5}$ is confident that a suitable contribution, or set of contributions, has been created, but there is still the issue of the examination process to deal with.

While $\mathrm{PhD}$ assessment processes vary across institutions internationally, there is usually a degree of independence or 'externality' involved, which in countries such as Australia and the UK includes at least one examiner from another university. Because Juno, Julius and Augustus were all members of staff, two external examiners were required instead of the usual one. Examiners are in a 'powerful brokerage position' (Baptista et al., 2015, 56).

One thing to bear in mind is that the examiners might be more relaxed about the age of the data than the supervisor fears. After all, many are used to reviewing for journals papers that have been a long time in the writing and revising. Moreover - although some examiners might be less ready to recognise this than others - they are used to citing and relying on research published some years before and hence based on even older data, when seeking to make their own new research contributions. In many cases they will be referring to this research as being of contemporary relevance, not just an interesting feature of the development of a particular literature.

Furthermore, it is not unusual for a doctoral candidate to bring to the examiners' attention one or more aspects of their research that has already been published in a respected form, not least because this makes it more difficult for the examiners to say there is no merit in the research. In the case of a delayed doctorate, if a published contribution was made at an earlier stage of the research process, this might have a positive effect on the examiners' attitude

\footnotetext{
${ }^{5}$ I have been assuming a single supervisor for the purposes of exposition, but I recognise that this is usually not the case.
} 
towards the work (assuming nothing in this conflicts with any of the university's particular regulations); this might have helped in Julius' $\mathrm{PhD}$, where two papers had been published in respected journals at the time of the first phase of the research. ${ }^{6}$

Nevertheless, if there are concerns about the examiners' possible reaction, as is likely, it seems appropriate to put them on notice about the age of the data when asking them if they might be interested in examining the imminent doctoral submission. This might look like seeking out a sympathetic examiner or 'opinion shopping', but if done with a clear conscience, it is little different from the practice of some enlightened universities of asking examiners to accept their appointment only if they are amenable to the paradigm or research tradition within which the doctorate has been prepared $;^{7}$ they are being asked to warrant that they will not reject the work on the basis of a general principle, but will examine the thesis on its own merits - which in the case of a doctorate containing 'old' data would include the reasonableness of using those data for the contribution claimed.

In the UK, it is common for the supervisor to approach a potential examiner to enquire whether they might be willing and able to undertake the role. It is usual to provide a brief description of the research and any useful contextual information, which could include the age of the data. In the case of Juno I mentioned some of the problems she had faced and then addressed the issue of the data in the following terms in my email to the prospective external examiners:

The research itself was undertaken many years ago and is no longer particularly relevant to the commercial setting to which it relates, but the contribution is focused very much on the use of modelling tools and engages

\footnotetext{
${ }^{6}$ An alternative route for Julius would have been to pursue a $\mathrm{PhD}$ by publication (Bradley, 2009; Mason \& Merga, 2018), but for various reasons we thought that the conventional thesis route was preferable.

${ }^{7}$ I do not know how common this is, but it was an aspect of the process at one Australian university for which I examined a PhD.
} 
with current literature, so my view is that the age of the data, while not ideal, is not an issue per se.

I was thus putting the potential examiners on notice about the issue of the age of the data, giving them the opportunity to turn down the invitation if that would be a problem for them as a matter of principle (or as a knee-jerk reaction) - though it still remained for the thesis to be convincing about the contributions claimed, which Juno defended extremely well at the viva.

An alternative approach would be to avoid the issue of the age of the data by simply not referring to it in the thesis. While this would not be feasible with data like economic statistics, where the date relate to particular years, it might be possible for primary data from questionnaire surveys or interviews, for example. However, this approach raises an ethical question, especially as transparency might be deemed an essential feature of good research. Moreover, if in response to a direct question, or as an implication of some of the discussion during the viva, it became apparent to the examiners that the data were significantly older than they might reasonably have expected, that might cause difficulties. If they felt that they had been deceived in some way, or if they had an automatic aversion to old data anyway, the candidate could have a serious problem. Thus there are also instrumental reasons for being transparent about the age of the data. To paraphrase Richard Whately, sometime Archbishop of Dublin, honesty is the best policy, even if whoever is governed by that maxim is not an honest person.

\section{Conclusion}

There are many reasons why a doctorate might not be completed, and surprisingly few are a straightforward journey from start to finish. Jones (2013) notes that attrition can happen at any stage, even where a significant amount of work has been done and considerable progress 
made. Likewise, many planned journal articles do not proceed as planned once the data have been collected. As explored in this paper, one of the worries that can emerge along the way is that the data have become too old - or might be perceived to be too old - to make a sufficient contemporary contribution to knowledge. Other things being equal, the likelihood of being able to make a sufficient contribution will decline with the age of the data. However, it is difficult, not to say impossible, to specify how old is 'too old'; it is not the age of the data that is the issue but the potential contemporary relevance of some form of analysis of the data to the literature as it now stands. Making that judgement as a supervisor is not always easy though, and I would not wish to imply, through the use of three successful vignettes, that there will always be a viable route through to a sufficient contribution and completion of the PhD. Very few submitted doctoral theses actually fail (Cantwell \& Scevak, 2004; Mullins \& Kiley, 2002), but this does not mean that it never happens (some do fail or only a master's degree is awarded), and it very likely reflects the gatekeeping role of the supervisor (Cantwell \& Scevak, 2004), who will often advise a student to withdraw (or support the student's proposal to withdraw) if they see little prospect of completion. In a case of ageing data, the supervisor's ability to judge whether - and, if so, how - a piece of research can continue to go forward is likely to be much greater than that of the research student, who lacks the necessary experience and expertise. It is a serious responsibility that the supervisor has, to be neither too pessimistic nor too optimistic about the prospects of success. It is hoped that this article provides some assistance for supervisors in thinking through the relevant issues and making good choices about the advice they provide.

Assuming that the data still seem to hold some potential as the basis for a contribution to knowledge at doctoral level, the main points that have emerged from the analysis may be summarised in the following advice to supervisors: 
1) Ensure that you and the research student are clear about the current state of the literature and how the research could fit in now.

2) Determine which research questions should be retained, modified or jettisoned; and whether new research questions should be added.

3) Assess the strengths and weaknesses of the existing data. Decide whether they are sufficient or need supplementing for the original or, especially, the updated set of research questions.

4) Ensure that the analysis of the data is sufficient to answer the research questions and accords with current good practice.

5) Check that the written material in the thesis reflects the current aims and objectives and does not contain unnecessary or confusing remnants of old plans and drafts.

6) Identify any possible methodological contributions, but be careful to present a strong case for any claims made.

7) Be open with examiners and give those who do not share your view about the potential contemporary relevance of 'old' data the opportunity to decline an invitation to examine.

In addition to the above guidance, the stories of Juno, Julius and Augustus should provide encouragement that a successful outcome might be possible when serious concern has arisen about the age of the data collected for a doctoral project. I suppose it should be acknowledged that the experiences of the three protagonists in the vignettes, not to mention Brian May, happened some years ago; but I suggest that the contribution of this paper would not be affected by whether their PhDs were completed last year or a decade or two ago. QED? Unfortunately, there will be cases where it is adjudged that it is probably not possible to produce a passable $\mathrm{PhD}$ thesis from the research already undertaken, but hopefully the 
material in this paper will help the decision about whether or not to proceed to be made both consciously and wisely.

Finally, I invite other business school supervisors to reflect on and share their experiences of deciding whether, and how, old empirical data can be used successfully in a delayed doctoral submission. Alternatively, more systematic research into supervisors' and former $\mathrm{PhD}$ students' experience would be welcome, including cases where it was decided not to proceed because of the age of the data.

\section{Acknowledgements}

I would like to acknowledge the contribution of 'Juno', 'Julius' and 'Augustus' and to thank them for their support in the writing of this paper. They know who they are.

\section{References}

Baptista, A., Frick, L., Holley, K., Remmik, M., \& Tesch, J. (2015). The doctorate as an original contribution to knowledge: considering relationships between originality, creativity, and innovation. Frontline Learning Research, 3(3), 55-67.

Biggs, M. (2005). Rescue supervision. Idade da Imagem, 3(2), 136-140.

http://uhra.herts.ac.uk/handle/2299/4716 (Accessed 8 January 2018).

Bradley, G. (2009). Publish and be doctor-rated: the PhD by published work. Quality Assurance in Education, 17(4), 331-342.

Bryman, A., \& Bell, E. (2015). Business research methods (4 ${ }^{\text {th }}$ ed.). Oxford: Oxford University Press. 
Cantwell, R., \& Scevak, J. (2004). Discrepancies between the "ideal" and "passable" doctorate: supervisor thinking on doctoral standards. Australian Association for Research Education Annual Conference, Melbourne, Australia, November.

Clarke, G., \& Lunt, I. (2014). The concept of 'originality' in the Ph.D.: how is it interpreted by examiners? Assessment \& Evaluation in Higher Education, 39(7), 803-820.

Coulter, A. (1995). General practice fundholding: time for a cool appraisal. British Journal of General Practice, 45(392), 119-120.

Cowton, C. J. (1998). The use of secondary data in business ethics research. Journal of Business Ethics, 17(4), 423-434.

Cryer, P. (2000). The research student's guide to success ( $2^{\text {nd }}$ ed.). Buckingham: Open University Press.

Ennew, C., Whynes, D., Jolleys, J., \& Robinson, P. (1998). Entrepreneurship and innovation among GP fundholders. Public Money and Management, 18(1), 59-64.

Farrell, C., Oertona, S., \& Plant, E. (2018). Doing a doctorate in business administration: the case for critical reflexivity. International Journal of Management Education, 16(3), 370-379.

Finn, J. A. (2005). Getting a PhD: an action plan to help manage your research, your supervisor and your project. Abingdon: Routledge.

Frankfort-Nachmias, C., Nachmias, D., \& DeWaard, D. (2015). Research methods in the social sciences $\left(8^{\text {th }}\right.$ ed.). New York: Worth.

Gardner, S. K., \& Gopaul, B. (2012). The part-time doctoral student experience. International Journal of Doctoral Studies, 7, 63-78.

Golde, C. M. (2000). Should I stay or should I go: student descriptions of the doctoral attrition process. Review of Higher Education, 23(2), 199-277. 
Golding, C. (2017). Advice for writing a thesis (based on what examiners do). Open Review of Educational Research, 4(1), 46-60.

Halse, C., \& Malfroy, J. (2010). Retheorizing doctoral supervision as professional work. Studies in Higher Education, 35(1), 79-92.

Heaton, J. (2008). Secondary analysis of qualitative data: an overview. Historical Social Research, 33(3), 33-45.

Holbrook, A., Bourke, S., \& Fairbairn, H. (2015). Examiner reference to theory in PhD theses. Innovations in Education and Teaching International, 52(1), 75-85.

Jones, M. (2013). Issues in doctoral studies - forty years of journal discussion: where have we been and where are we going? International Journal of Doctoral Studies, 8, 83-104.

Lahenius, K. (2012). Communities of practice supporting doctoral studies. International Journal of Management Education, 10(1), 29-38.

Lambotte, F., \& Meunier, D. (2013). From bricolage to thickness: making the most of the messiness of research narratives. Qualitative Research in Organizations and Management: An International Journal, 8(1), 85-100.

Levecque, K., Anseel, F., De Beuckelaer, A., Van der Heyden, J., \& Gisle, L. (2017). Work organization and mental health problems in PhD students. Research Policy, 46(4), 868-879. Mason, S., \& Merga, M. (2018). A current view of the thesis by publication in the humanities and social sciences. International Journal of Doctoral Education, 13, 139-154.

Mullins, G., \& Kiley, M. (2002). 'It's a PhD, not a Nobel Prize': how experienced examiners assess research theses. Studies in Higher Education, 27(4), 369-386.

Parker-Jenkins, M. (2016). Mind the gap: developing the roles, expectations and boundaries in the doctoral supervisor-supervisee relationship. Studies in Higher Education, 43(1), 57-71. 
Petre, M., \& Rugg, G. (2010). The unwritten rules of PhD research. Maidenhead: Open University Press.

Phillips, E. M., \& Pugh, D. S. (2015). How to get a PhD: A handbook for students and their supervisors $\left(6^{\text {th }}\right.$ ed.). Maidenhead: Open University Press.

Van de Schoot, R., Yerkes, M. A., Mouw, J. M., \& Sonneveld, H. (2013). What took them so long? Explaining PhD delays among doctoral candidates. PLoS One, 8(7). doi: 10.1371/journal.pone.0068839.

Stewart, D. W., \& Kamins, M. A. (1993). Secondary research: Information sources and methods $\left(2^{\text {nd }}\right.$ ed. $)$. Newbury Park, CA: SAGE.

Stolowy, H. (2017). Letter from the Editor: why are papers desk rejected at European Accounting Review? European Accounting Review, 26(3), 411-418.

Wisker, G. (2015). Developing doctoral authors: engaging with theoretical perspectives through the literature review. Innovations in Education and Teaching International, 52(1), 64-74. 